\title{
Understanding agarwood formation and its challenges
}

\begin{abstract}
The resinous portion of the Aquilaria tree is called agarwood, a valuable non-timber product being used as medicine and incenses in Asia, Middle East, and Europe. Driven by high demand, the wild resources of agarwood-producing trees have been greatly threatened. This fragrant product contains many aromatic substances and is obtained from the pathological conditions of the wood of living trees. The knowledge regarding the technology for inducing agarwood and its continuous formation in the tree is still limited. To conserve the wild Aquilaria spp. and to supply sustainable amount of agarwood, cultivation of Aquilaria trees in combination with induction through artificial technique is seen as the best approach. In this chapter we will discuss the fundamentals of agarwood formation in the producing trees, the molecular pathway in its synthesis, current methods applied for agarwood induction in cultivated trees, and finally the factors influencing agarwood yield and quality.
\end{abstract}

Keyword: Methyl jasmonate; Fusarium solani; Methylerythritol phosphate; Interxylary phloem; Lasiodiplodia theobromae 